\title{
Chemical stabilization of Cd-contaminated soil using fresh and aged wheat straw biochar
}

Dilani Rathnayake ${ }^{1 *}$, Filipe Rego ${ }^{2}$, Reinhart Van Poucke ${ }^{3}$, Anthony V. Bridgwater ${ }^{2}$, Ondřej Mašek ${ }^{4}$, Erik Meers ${ }^{3}$, Jiawei Wang ${ }^{2}$, Yang Yang ${ }^{2}$, Frederik Ronsse ${ }^{1}$

${ }^{1}$ Thermochemical Conversion of Biomass Research Group, Department of Green Chemistry and Technology, Faculty of Bioscience Engineering, Ghent University, 653, Coupure Links, 9000, Ghent, Belgium.

${ }^{2}$ Bioenergy Research Group, EBRI, Aston University, Birmingham, B4 7ET, United Kingdom.

${ }^{3}$ Laboratory of Analytical Chemistry and Applied Ecochemistry, Department of Green Chemistry and Technology, Faculty of Bioscience Engineering, Ghent University, 653, Coupure Links, 9000, Ghent, Belgium.

${ }^{4}$ UK Biochar Research Centre, School of Geosciences, Crew Building, The King's Buildings, University of Edinburgh, Edinburgh, EH9 3FF.

*Corresponding author: Dilani Rathnayake (Dilani.RathnayakeMudiyanselage@UGent.be), Thermochemical Conversion of Biomass Research Group, Department of Green Chemistry and Technology, Faculty of Bioscience Engineering, Ghent University, 653, Coupure Links, 9000, Ghent, Belgium.

\section{Highlights}

- Severity of surface transformation after aging was high in low temperature wheat straw biochar compared to biochar produced at higher temperatures

- Aged wheat straw biochars performed better than the fresh biochars at $500{ }^{\circ} \mathrm{C}$ and $600{ }^{\circ} \mathrm{C}$ production temperatures while fresh wheat straw biochar performed better than the aged form only at $400{ }^{\circ} \mathrm{C}$

- Alkalinity and surface functionality in wheat straw biochar played an important role in immobilization of Cd in pore water

\section{Abstract}

Metal mining and smelting activities can introduce a substantial amount of potentially toxic elements (PTE) into the environment that can persist for an extended period. That can limit the productivity of the land and creates dangerous effects on ecosystem services. The effectiveness of wheat straw biochar to immobilize $\mathrm{Cd}$ in contaminated soil due to metal smelting activities was investigated in this study. The biochar carbon stability and long-term provisioning of services depend on the biochar production conditions, nature of the feedstock, and the biotic and abiotic environmental conditions in which the biochar is being used. Within this context, three types of 
wheat straw biochar were produced using a screw reactor at $400{ }^{\circ} \mathrm{C}, 500{ }^{\circ} \mathrm{C}$, and $600{ }^{\circ} \mathrm{C}$, and tested in a laboratory incubation study. Soil was amended with 2 wt. \% of biochar. Both fresh and aged forms of biochar were used. Biochars produced at lower temperatures were characterized by lower $\mathrm{pH}$, a lower amount of stable $\mathrm{C}$, and higher amounts of acidic surface functional groups than the freshly produced biochars at higher production temperatures. At the end of the six months of incubation time, compared to the soil only treatment, fresh and aged forms of wheat straw biochar produced at $600{ }^{\circ} \mathrm{C}$ reduced the $\mathrm{Cd}$ concentration in soil pore water by $22 \%$ and $15 \%$ respectively. Our results showed that the aged forms of biochar produced at higher production temperatures $\left(500{ }^{\circ} \mathrm{C}\right.$ and 600 $\left.{ }^{\circ} \mathrm{C}\right)$ immobilized $\mathrm{Cd}$ more efficiently than the aged forms of lower temperature biochar $\left(400^{\circ} \mathrm{C}\right)$. The findings of this study provide insights to choose the production parameters in wheat straw biochar production while considering their aging effect to achieve successful stabilization of $\mathrm{Cd}$ in contaminated soils.

Keywords: Wheat straw biochar, Accelerated aging, Soil remediation, Biochar stability, Cd contaminated soil

\section{Introduction}

Contaminated soil and groundwater can cause adverse impacts on flora and fauna in the surrounding environment. The presence of an elevated amount of potentially toxic elements (PTE) in the soil compared to the natural level is one of the main reasons for soil pollution (Beesley et al., 2011). Soil pollution due to PTEs can happen due to various reasons (e.g. anthropogenic activities such as mining and smelting of metals, mismanagement of hazardous waste, disposal of sewage sludge, waste incineration and chemical waste released from industry or agriculture) (Eugenio et al., 2018; WHO, 2007). The risk and impact posed by PTEs are not solely dependent on the total concentration of a particular PTE in soil. The bioavailable fraction (of a specific PTE) to plants and animals depend on multiple factors, such as soil organic matter content, soil pH, and the soil's cation exchange capacity (Meers et al., 2005). In this context, the remediation of contaminated lands needs to be performed to minimize the harmful impacts on the environment.

There are various in-situ and ex-situ methods being used to remediate contaminated soil. Depending on the scenario, a single or a combination of chemical (e.g. oxidation, reduction, pH manipulation), physical (e.g. solidification, washing and treatment) or biological (e.g. phytostabilization, land farming, phytodegradation) remediation methods can be used as a soil remediation process (Ahmad et al., 2014). Sustainable remediation of soil will help to eliminate the risks associated with the contaminants safely, while maximizing the socio-economic and environmental benefits (Beesley et al., 2011; Eugenio et al., 2018). In this context, biochar as an organic soil amendment is becoming popular due to its various advantageous characteristics for contaminated soil remediation (Palansooriya et al., 2020). 
Biochar is a product of pyrolysis (together with non-condensable pyrolysis gases and bio-oil). Production of biochar is carried out in an oxygen-limited or oxygen-free environment in a temperature range of $350{ }^{\circ} \mathrm{C}$ to 700 ${ }^{\circ} \mathrm{C}$ (Crombie et al., 2013). Production of biochar provides a more sustainable and economical approach when cogeneration and utilization of non-condensable gases and bio-oil is integrated to the system (Lehmann and Joseph, 2009). Often, non-condensable pyrolysis gas is used for power generation, fuel production, hydrogen and synthetic gas production. On the other hand, bio-oil can be used to derive bio-based platform chemicals, sustainable fuels and to generate combined heat and power (Masek, 2016). The quantity and physicochemical properties of these pyrolysis products vary with the production conditions (Ronsse et al., 2013).

When it comes to biochar, it is characterized by high stability due to a high aromatic carbon content (thus, resistant to biodegradation), a high cation exchange capacity and a high $\mathrm{pH}$. All these physicochemical properties of biochar depend on the feedstock material and pyrolysis production conditions such as production temperature and the residence time at production temperature (Mašek et al., 2013; Zhao et al., 2013). To have a consistent quality of biochar over time, production parameters and feedstock materials should be chosen and monitored correctly (Crombie et al., 2013; Ronsse et al., 2013). Biochars produced from different feedstock materials under different pyrolysis production conditions have been studied for the remediation of PTE contaminated soil all over the world (Ahmad et al., 2014; Lomaglio et al., 2018; Van Poucke et al., 2018). Biochar immobilizes or stabilizes the potentially toxic metals in the soil in various ways, such as through ion exchange, complexation by functional groups, physical adsorption, and precipitation (Bandara et al., 2019). The liming potential of biochar, due to its alkaline $\mathrm{pH}$, has an important effect on PTE mobility in contaminated soils (Qi et al., 2018).

To facilitate the efficient remediation of contaminated soil, identification of the mechanisms behind PTE immobilization with different soil amendments is important. Moreover, identification of the optimum pyrolysis production conditions that result in biochar with the desired characteristics (PTE immobilization) is also essential (Wang et al., 2020). Therefore in this study, biochars produced at different pyrolysis production temperatures were assessed as a remediation tool. The long-term provisioning of biochar services mainly depends on its stability (Dharmakeerthi et al., 2015; Liang et al., 2008). As mentioned above, biochar is highly recalcitrant to biodegradation due to the highly aromatic nature of its chemical composition. Long term soil incubation studies with biochar in laboratory scale and field-scale studies provide more realistic information regarding its stability compared to short-term laboratory scale incubation studies (Budai et al., 2013). However, these methods could take a lot of time to draw conclusions regarding the stability of biochar and its potential for remediating PTE contaminated soils. Hence, biochar stability proxies have been developed to assess biochar stability directly or 
indirectly in a quick way. One such proxy is the "Edinburgh stability tool", an accelerated aging method of biochar based on its initial total carbon content. The chemical biochar aging procedure in the Edinburgh stability tool can be used as a "proxy for environmental aging of biochar for approximately 100 years under temperate conditions" (Cross and Sohi, 2013). Hydrogen peroxide, which is an inexpensive and strong oxidizer, is used as an oxidation agent in this char aging procedure (Huff and Lee, 2016). A comparison of the carbon content in freshly produced biochar versus aged biochar gives an idea about the stability in long-term soil applications, including soil remediation. Changes of a biochar's initial characteristics through aging are influenced by the biochar production parameters, the nature of the feedstock material and the type of soil used (Heitkötter and Marschner, 2015). Even though the impacts of fresh biochar on soil properties are well documented, less is known about the long-term behavior of biochar in soil (Dong et al., 2017; He et al., 2019).

Aging has a significant impact on the biochar surface functionalities. Due to the aging process, the aliphatic-toaromatic compound ratios in biochar can change (Rechberger et al., 2017). Besides, the aging of biochar reduces the $\mathrm{pH}$ and increases oxygen and hydrogen-containing surface functional groups, increases the surface smoothness and hydrophilic nature of biochar, and increases the cation exchange capacity (Cao et al., 2017; Dong et al., 2017; Mukherjee et al., 2014; Rechberger et al., 2017). Therefore, the experimental results obtained using fresh biochar may not be relevant or accurate for the prediction or assessment of the long-term impacts of biochar (Bakshi et al., 2016). Laboratory aging of biochar can be used to assess the long-term impacts of biochar on soil properties (Lawrinenko et al., 2016). Within this context, both fresh and artificially aged biochars produced under different production conditions and a soil contaminated with $\mathrm{Cd}$ due to historic metal smelting activities, were used in this study. The objective of this study is to assess the effectiveness of the fresh and aged wheat straw biochar produced under different pyrolysis temperatures to immobilize $\mathrm{Cd}$ in the contaminated soil.

\section{Materials and methods}

\subsection{Soil characterization}

The soil used in this study was sampled from the Campine area $\left(51^{\circ} 12^{\prime} 41^{\prime \prime} \mathrm{N} ; 5^{\circ} 14^{\prime} 32^{\prime \prime} \mathrm{E}\right)$ which is situated between the northeast of Belgium and the southern part of the Netherlands. The soil samples were collected from the top layer $(0-25 \mathrm{~cm})$ and this soil was exposed to atmospheric deposition of PTEs such as $\mathrm{Cd}$ and $\mathrm{Zn}$ due to local metal smelting activities carried out in the past (Meers et al., 2010). Physicochemical properties of the air dried and sieved soil $(<2 \mathrm{~mm})$ used in this study are summarized in Table 1. Soil $\mathrm{pH}$ was analyzed in a 1:5 (soil: solution) ratio using a Jenway combined $\mathrm{pH}$ and electrical conductivity (EC) meter. Pseudo total elemental concentration in the soil was analyzed after aqua regia digestion of which the procedure is described in Van Ranst et al., (1999). 

clay as reported by Meers et al., (2010).

\begin{tabular}{lll}
\hline Parameter & unit & value \\
\hline Sand & $\%$ & 88 \\
$\mathrm{Silt}$ & $\%$ & 8 \\
$\mathrm{Clay}$ & $\%$ & 4 \\
$\mathrm{pH}(1: 5)$ & - & $6.9 \pm 0.1$ \\
$\mathrm{Cd}$ & $\mathrm{mg} / \mathrm{kg}$ & $8 \pm 0.1$ \\
$\mathrm{Cr}$ & $\mathrm{mg} / \mathrm{kg}$ & $11 \pm 0.2$ \\
$\mathrm{Cu}$ & $\mathrm{mg} / \mathrm{kg}$ & $20 \pm 0.1$ \\
$\mathrm{Mn}$ & $\mathrm{mg} / \mathrm{kg}$ & $42 \pm 0.5$ \\
$\mathrm{Ni}$ & $\mathrm{mg} / \mathrm{kg}$ & $3 \pm 0.1$ \\
$\mathrm{~Pb}$ & $\mathrm{mg} / \mathrm{kg}$ & $190 \pm 0.3$ \\
$\mathrm{Zn}$ & $\mathrm{mg} / \mathrm{kg}$ & $470 \pm 1.8$ \\
\hline
\end{tabular}

\subsection{Biochar production}

122 Wheat straw pellets with an average diameter of $0.8 \mathrm{~cm}$ and a maximum length of $1.6 \mathrm{~cm}$ were provided by 123 Agrodieren Company located near Ghent, Belgium. Neither additives nor binders were used during the production of these pellets. The wheat straw pellets were used in their received form for slow pyrolysis experiments. Pyrolysis experiments were conducted in a bench-scale (300 g/h) screw reactor at Aston University. Biochar samples were produced at $400{ }^{\circ} \mathrm{C}, 500{ }^{\circ} \mathrm{C}$ and $600{ }^{\circ} \mathrm{C}$, and with a solid residence time of 3 minutes at the highest treatment temperature. After production, the biochars were stored in plastic containers. Details about the reactor system and the slow pyrolysis process can be found in previous publications (Yang et al., 2018; Yu et al., 2016).

\subsection{Accelerated aging of wheat straw biochar samples}

Biochar samples were subjected to accelerated aging which is equal to the aging of biochar under approx. 100 years in temperate soil environment using the method described in Cross and Sohi, (2013). Briefly, finely ground biochar samples were oven-dried at $80^{\circ} \mathrm{C}$ for 18 hours to eliminate moisture. Then, biochar samples were analyzed for total $\mathrm{C}$ content according to the method described in section 2.4.2. Then, a biochar sample representing $0.1 \mathrm{~g}$ of $\mathrm{C}$ was weighed into a glass test tube and 0.01 moles of $\mathrm{H}_{2} \mathrm{O}_{2}$ and $7 \mathrm{~mL}$ of distilled water were added into the test tube. After mixing the contents of the tube, samples were heated at $80{ }^{\circ} \mathrm{C}$ for 48 hours. After the heating step, 
the tubes were dried at $105{ }^{\circ} \mathrm{C}$ in a conventional oven to evaporate the solution inside. Then, the biochar samples were washed with deionized water three times to remove the residual $\mathrm{H}_{2} \mathrm{O}_{2}$ in the mixtures. Finally, these artificially aged samples were oven-dried at $105^{\circ} \mathrm{C}$ for 24 hours and were subsequently used for soil incubation. Aged biochar samples (A) were named as A400, A500 and A600. Fresh biochars (F) were denoted as F400, F500 and F600.

\subsection{Biochar characterization}

\subsubsection{Proximate analysis}

Proximate analysis of biochar was done in triplicate according to the modified version of ASTM D1762-84 method described in Enders et al., (2017). Porcelain crucibles with biochar samples were covered and heated in a conventional drying oven at $105{ }^{\circ} \mathrm{C}$ for 18 hours to determine the moisture content by weight difference. Afterwards, covered crucibles with biochar dried at $105{ }^{\circ} \mathrm{C}$ were introduced into a muffle furnace heated to 950 ${ }^{\circ} \mathrm{C}$ and samples were kept at $950{ }^{\circ} \mathrm{C}$ for 10 minutes to determine the volatile matter content in biochar. The ash content was determined by keeping the crucibles (uncovered) containing biochar at $750{ }^{\circ} \mathrm{C}$ for 6 hours in the muffle furnace followed by measuring the ash weight. Finally, the fixed carbon content is determined by difference based on volatile matter and ash content:

Fixed carbon content $(\%, \mathrm{~d} . \mathrm{b})=(100-$ Ash content - Volatile matter content $)$

\subsubsection{Elemental analysis of biochar samples}

Biochar samples were analyzed in triplicate for C, H, N, and S by using a Flash 2000 total elemental analyzer (Thermo Scientific, USA). The oxygen content was determined by difference on a dry ash-free basis. 2, 5-bis (5tert-butyl-benzoxazol-2-yl) thiophene (BBOT) was used as standard reference material during CHNS analysis.

\subsection{3. pH and EC of biochar samples}

$\mathrm{pH}$ and electrical conductivity (EC) of biochar samples were measured in a 1:20 (w/v) ratio with deionized water after shaking for 1 hour and 30 minutes using a Jenway combined $\mathrm{pH}$ and $\mathrm{EC}$ meter. The analysis was performed in triplicate for each sample.

\subsubsection{FTIR analysis of biochar samples}

The samples were analyzed qualitatively for surface chemical functionalities using Fourier Transform Infra-Red (FTIR), with a Perkin Elmer Frontier FTIR Spectrometer, with PIKE Technologies GladiATR (Attenuated Total Reflectance) and Spectrum software. The analyses were performed from a wavenumber of 4000 to $400 \mathrm{~cm}^{-1}$, with $4 \mathrm{~cm}^{-1}$ resolution using 16 scans. 


\subsection{Soil incubation experiment and soil pore water extraction}

A six-month laboratory soil incubation experiment was conducted to assess the $\mathrm{Cd}$ immobilization in contaminated soil with biochar. Four grams of biochar (either fresh or aged) were mixed with $196 \mathrm{~g}$ of soil. A control treatment with $200 \mathrm{~g}$ of soil was also included. The samples were kept in $0.5 \mathrm{~L}$ wide-mouth mason jars covered with parafilm and incubated for six months. The soil moisture content was adjusted to $70 \%$ of the water holding capacity at the beginning of the incubation and maintained over the incubation period. The seven treatment combinations (6 amendments and one control soil) were replicated 3 times. Rhizon extractions were done once a month for up to six months to extract the pore water in the treatment mixtures using soil moisture samplers (Eijkelkamp soil moisture samplers, Giesbeek, The Netherlands). After each rhizon extraction, the moisture content of the mixture was readjusted with deionized water by correcting the weight of the jars containing the soil and biochar mixture.

\subsection{Sequential extraction}

At the end of the six months of incubation, all the treatments were subjected to sequential extraction, according to the method described in (Rauret et al., 1999). Briefly, the exchangeable and weak acid-soluble fraction was extracted using 0.11 M acetic acid (VWR chemicals, Belgium). The reducible fraction (Fe and Mn bound oxides and hydroxides) was extracted using 0.5 M hydroxylamine hydrochloride (Sigma Aldrich, Belgium). The oxidizable fraction (organic matter bound) was extracted using 8.8 M hydrogen peroxide (VWR chemicals, Belgium) and $1 \mathrm{M}$ ammonium acetate (VWR chemicals, Belgium). Then, the residual fraction was determined using the Aqua regia soil digestion method (Rauret et al., 1999). Finally, all the extracted samples were analyzed for $\mathrm{Cd}^{2+}$ using ICP-OES (Varian Vista-MPX CCD Simultaneous, Varian Inc., Victoria, Australia) and ICP-MS (ELAN DRCe, Perkin Elmer SCIEX, Waltham, MA, USA). Initial soil sample weights were corrected for moisture content and the results are presented on a percentage dry weight basis at $105{ }^{\circ} \mathrm{C}$.

\subsection{Statistical analysis}

Statistical analyses were performed using IBM's SPSS 22 and Microsoft Excel softwares. The difference in soil pore water $\mathrm{pH}$ values, $\mathrm{Cd}$ concentrations in different soil fractions, and $\mathrm{Cd}$ concentrations in soil pore water between different treatments were assessed using Tukey's post hoc test at a significance level of 0.05 . This was done after a one-way ANOVA test. Prior to the ANOVA test, normality was tested using Shapiro-Wilks test for normality and Leven's test. 


\section{Results and discussion}

194

195

196

197

\subsection{Biochar characteristics}

The chemical characterization of biochar was performed in order to assess the changes in biochar with pyrolysis production temperature and after accelerated aging. Results are shown in Table 2.

Table 2. Characteristics of biochars used in this study (mean \pm standard deviation, $n=3$ ).

\begin{tabular}{lccccccc}
\hline & Unit & F400 & A400 & F500 & A500 & F600 & A600 \\
\hline Volatile matter & $\%$ (d.b) & $35.2 \pm 3.1$ & $49.1 \pm 2.2$ & $30.3 \pm 1.8$ & $43.1 \pm 2.5$ & $19.5 \pm 2.7$ & $34.3 \pm 1.1$ \\
Ash & $\%$ (d.b) & $12.2 \pm 1.2$ & $11.2 \pm 0.1$ & $15.5 \pm 2.1$ & $13.3 \pm 0.5$ & $17.1 \pm 1.3$ & $16.3 \pm 0.8$ \\
Fixed carbon & $\%$ (d.b) & $53.1 \pm 2.1$ & $40.2 \pm 1.1$ & $55.4 \pm 1.6$ & $44.2 \pm 2.4$ & $64.1 \pm 3.2$ & $50.3 \pm 2.5$ \\
Total C & $\%$ (d.b) & $59.3 \pm 2.7$ & $48.1 \pm 1.3$ & $66.2 \pm 3.1$ & $57.5 \pm 0.6$ & $71.2 \pm 1.5$ & $68.1 \pm 2.1$ \\
Total H & $\%$ (d.b) & $0.5 \pm 0.1$ & $0.7 \pm 0.1$ & $0.6 \pm 0.2$ & $1.0 \pm 0.1$ & $0.2 \pm 0.0$ & $0.5 \pm 0.1$ \\
Total N & $\%$ (d.b) & $4.0 \pm 0.2$ & $3.1 \pm 0.5$ & $3.2 \pm 0.2$ & $2.2 \pm 0.3$ & $3.1 \pm 0.1$ & $2.0 \pm 0.1$ \\
Total O & $\%$ (d.b) & $24.5 \pm 1.5$ & $37.3 \pm 2.2$ & $15.4 \pm 1.5$ & $26.8 \pm 0.9$ & $8.8 \pm 0.5$ & $13.5 \pm 1.2$ \\
H/C molar ratio & - & $0.1 \pm 0.0$ & $0.2 \pm 0.0$ & $0.1 \pm 0.0$ & $0.2 \pm 0.0$ & $0.03 \pm 0.0$ & $0.1 \pm 0.0$ \\
O/C molar ratio & - & $0.3 \pm 0.0$ & $0.6 \pm 0.0$ & $0.2 \pm 0.0$ & $0.3 \pm 0.0$ & $0.2 \pm 0.0$ & $0.1 \pm 0.0$ \\
pH (1:10) & - & $9.6 \pm 0.2$ & $5.1 \pm 0.1$ & $9.9 \pm 1.5$ & $6.9 \pm 1.1$ & $10.3 \pm 0.5$ & $8.6 \pm 1.3$ \\
EC (1:10) & $\mathrm{mS} / \mathrm{cm}$ & $1.4 \pm 0.1$ & $1.8 \pm 0.4$ & $2.2 \pm 0.1$ & $4.7 \pm 0.3$ & $3.4 \pm 0.1$ & $3.6 \pm 0.2$ \\
\hline
\end{tabular}

\subsection{1. pH and EC}

The $\mathrm{pH}$ and EC of biochar provide an indication of the alkalinity and salt concentration in biochar. It is well known that in general, with an increase in pyrolysis temperature, acidic functional groups on the surface of biochar (i.e., hydroxyl and carboxyl groups) are progressively being removed. At the same time, because of the volatilization of organic matter, the ash content increases at higher pyrolysis temperatures (Crombie et al., 2013; Nachenius et al., 2013). As a result, the remaining solid product becomes more alkaline (Weber and Quicker, 2018) and the biochar $\mathrm{pH}$ and $\mathrm{EC}$ increase. In this study, the biochar $\mathrm{pH}$ varied between 5.1 in A400 to 10.3 in F600. As expected, the biochar $\mathrm{pH}$ increased with an increase in pyrolysis temperature and decreased after aging. Huff and Lee, (2016) and Mia et al., (2017) reported that during the aging of biochar by using an oxidizing agent, surface functionalities like carboxylic, phenolic and ether groups can be created. These functional groups are acidic in nature and could introduce acidity into biochar. 
Depending on the aromaticity of biochar, the nature and quantity of the surface groups could vary. Lawrinenko et al., (2016) also reported that high-temperature biochar was more resistant to oxidation and to loss of anion exchange capacity than biochar produced at lower production temperatures. This is more likely the reason for the drastic $\mathrm{pH}$ reduction in $\mathrm{A} 400$ compared to $\mathrm{F} 400$. As a result of the formation of oxygenated functionalities on the surface of biochar induced by aging, the negative charge on the surface could increase. Carboxylate groups formed during oxidation can convert into carboxyl groups (Lawrinenko et al., 2016). A400 and A500 samples had slightly acidic $\mathrm{pH}$ and all the other biochar samples had highly alkaline $\mathrm{pH}$ values. Only the A400 sample had a $\mathrm{pH}$ lower than the soil $\mathrm{pH}$ value (Table 2). The electrical conductivity of the biochar samples ranged between $1.4 \mathrm{mS} / \mathrm{cm}$ in A400 to $3.6 \mathrm{mS} / \mathrm{cm}$ in A600. The EC of biochar increased with the pyrolysis production temperature and with the aging of biochar.

\subsubsection{Proximate composition}

221

The fixed carbon content of wheat straw biochar increased with an increase in pyrolysis production temperature. However, its value decreased after the aging procedure. In fresh biochar samples, fixed carbon content varied between 53\% (d.b) in F400 to 64\% (d.b) in F600. In aged biochar samples, fixed carbon content varied between 40\% (d.b) in A400 and 50\% (d.b) in A600 (Table 2). At higher pyrolysis production temperatures, the ash content in biochar samples was higher and the volatile matter content was lower. The highest ash content was in F600 (17\%, d.b.) and the lowest ash content was in A400 (11\%, d.b.). Volatile matter content was lowest for F600 (19\%, d.b), while the highest was observed for A400 (49\%, d.b). From these observations, it is clear that non-volatile ash accumulates in the biochar as the pyrolysis temperature increases while simultaneously, volatile matter is progressively removed. With accelerated aging, the ash content in biochar lowered and volatile matter content increased. However, the reduction in ash content after aging was not significant. During the aging with an oxidizing agent (which was in the form of an aqueous solution), removal of labile carbon and accessible salts could happen (Mia et al., 2017). Some salts and minerals attached to the biochar structure could become more labile and partial oxidation of fixed carbon to more labile forms could happen during the aging process (Mia et al., 2017). As a result, a decrease in fixed carbon content and ash content, together with an increase in volatile matter content occurs (Bakshi et al., 2016). This observation aligns well with the increase in $\mathrm{pH}$ and $\mathrm{EC}$ of biochar with pyrolysis production temperature and the decrease of $\mathrm{pH}$ and $\mathrm{EC}$ upon char aging.

\subsubsection{Elemental analysis}

238 The total $\mathrm{C}$ content in biochar samples ranged from $48 \%$ (d.b) in A400 to $71 \%$ (d.b) in F600 (Table 2). With the increase in pyrolysis production temperature, biochar total $\mathrm{C}$ content increased, and as a result, the $\mathrm{H} / \mathrm{C}$ molar ratio 
decreased. As the $\mathrm{H} / \mathrm{C}$ molar ratio is a proxy for biochar stability, it can be concluded that the stability of the biochar samples increased at higher production temperature (Budai et al., 2013). The total $\mathrm{N}$ content decreased with the pyrolysis temperature and after accelerated aging of biochar samples. This may be due to a loss of protein associated chemical functionalities (like amines and amides) in the feedstock with an increase in pyrolysis temperature. Due to the degradation of cellulose, hemicellulose, and lignin during pyrolysis, a release of volatiles occurs (Ronsse et al., 2015). As a result, the produced biochars had a more condensed aromatic structure with higher aromatic carbon content than the feedstock material. Elimination of $\mathrm{H}$ and $\mathrm{N}$ embedded in weaker (i.e. thermally labile) functional groups with an increase in pyrolysis temperature results in biochar with lower $\mathrm{H}$ and $\mathrm{N}$ contents (Crombie et al., 2013). With the increase in pyrolysis production temperature, $\mathrm{C}$ content in biochar and the degree of aromatization increase. As a result of that, oxygen functionalities on the biochar surface decrease (Chen et al., 2016). During the aging process, degradation of pyrrole and pyridine structures could happen. This may contribute to the observed reduction of $\mathrm{N}$ in aged biochar (Lawrinenko et al., 2016). Also, due to the $\mathrm{H}$ attachments by radical formation to the basal planes of condensed aromatic carbons, the total $\mathrm{H}$ content in aged biochar increases (de la Rosa et al., 2018). As aging progresses, surface functional groups containing oxygen are formed. As a result, total oxygen content in aged biochar increased (Lawrinenko et al., 2016) (Table 2).

\subsubsection{FT-IR analysis of biochar}

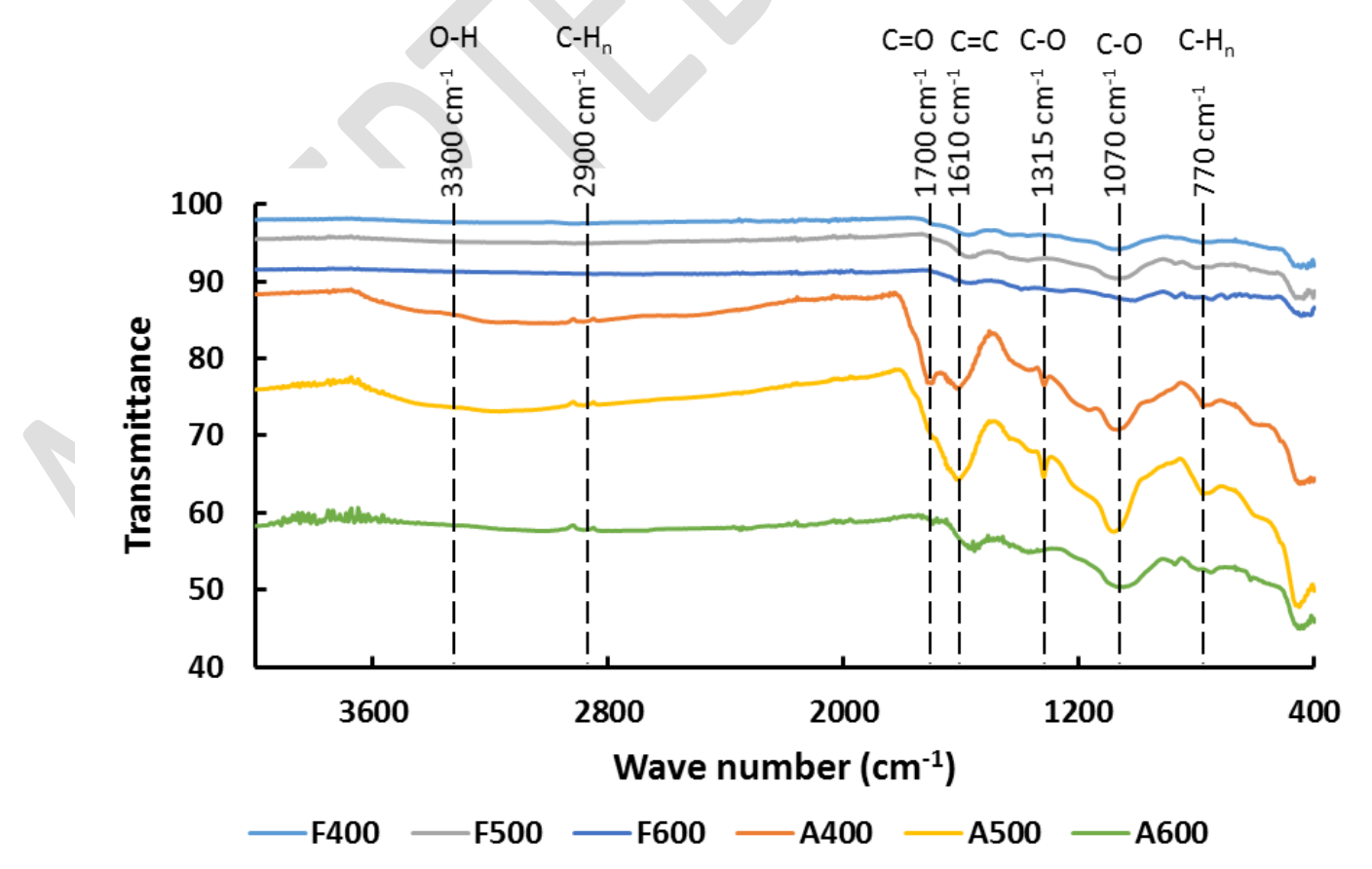

Fig. 1 FTIR spectra for the fresh (F) and aged (A) biochars produced from slow pyrolysis of wheat straw at 400, 500 and $600{ }^{\circ} \mathrm{C}$. 
The fresh and aged biochars from wheat straw were analyzed using FTIR to qualitatively determine surface chemical functionalities. The spectra are displayed in Fig 1. During the accelerated aging process of biochar, oxygen-containing surface functional groups are formed. Those functional groups can be acidic, neutral or alkaline in nature (Huff and Lee, 2016; Lawrinenko et al., 2016). Acidic functionalities that are created after aging, such as carboxylic, hydroxyl, quinone, phenolic, lactonic groups could make biochar more hydrophilic, with higher surface area and porosity (Beesley et al., 2011; Cheng et al., 2008). The aging-induced oxygen-containing functional groups may be responsible for lowering the biochar $\mathrm{pH}$ after aging (Table 2). However, the quantity and the nature of functional groups is based on the intensity of the aging treatment and the chemical agent used (Moreno-Castilla et al., 1995). According to that, aging with $\mathrm{H}_{2} \mathrm{O}_{2}$ produces more carbonyl and carboxylate functionalities (Beesley et al., 2011; Cheng et al., 2008). The increase in oxygen proportion by using $\mathrm{H}_{2} \mathrm{O}_{2}$ can be confirmed with elemental analysis (Table 2). Singh et al., (2014) also observed through XPS analysis, that biochar gained more carboxyl groups on its surface after aging. In the region of $\mathrm{O}-\mathrm{H}$ bond vibration at around $3300 \mathrm{~cm}^{-1}$, a band can be seen for the aged biochars, especially the ones produced at $400{ }^{\circ} \mathrm{C}$ and $500{ }^{\circ} \mathrm{C}$. This indicates an increase in the presence of alcohols and phenols. A lack of peaks in the region $2850-2950 \mathrm{~cm}^{-1}$, corresponding to the stretching vibration of $\mathrm{C}-\mathrm{H}_{\mathrm{n}}$ bonds, both for the fresh and aged biochars, indicates that aliphatic compounds had a relatively low presence in fresh biochars and that they were not produced by oxidation using $\mathrm{H}_{2} \mathrm{O}_{2}$. The intensity of aging of biochar (i.e. increase in O-containing surface functional groups) after treating with $\mathrm{H}_{2} \mathrm{O}_{2}$ is affected by the pyrolysis production conditions during biochar production and similar observations were reported by Cheng et al., (2008).

For wavenumbers around $1700-1800 \mathrm{~cm}^{-1}$, which correspond to $\mathrm{C}=\mathrm{O}$ bonds (carbonyls), some bands can be seen for the aged biochar produced at $400{ }^{\circ} \mathrm{C}$ pyrolysis temperature. There is also some bands in the aged $500{ }^{\circ} \mathrm{C}$ biochar, but not for the $600{ }^{\circ} \mathrm{C}$ aged biochar. This relates to the fact that the surface of the biochars produced at lower pyrolysis temperatures is more prone to chemical transformation by oxidation because more surface functionalities are present, thus enabling the creation of more O-containing compounds on the surface than the biochars obtained at higher pyrolysis temperatures. In the region of the spectrum between 1550 and $1650 \mathrm{~cm}^{-1}$, which corresponds to vibrating $\mathrm{C}=\mathrm{C}$ bonds (e.g. aromatics), there is a significant manifestation for the aged biochars from $400{ }^{\circ} \mathrm{C}$ and $500{ }^{\circ} \mathrm{C}$ pyrolysis, but not as significant for the $600{ }^{\circ} \mathrm{C}$ aged biochar or the fresh biochars. The presence of alcohols and carboxylic acids, and also esters and ethers, is indicated by the strong band located at $1000-1150 \mathrm{~cm}^{-1}$ and other peaks (e.g. around $1320 \mathrm{~cm}^{-1}$ ) at $1100-1320 \mathrm{~cm}^{-1}$ (vibration of C-O bonds). These regions have IR manifestations in the spectra for the aged biochars, and much less for the freshly-produced 
biochars. This is corroborated by the elemental analysis in Table 2, which shows increases of $\mathrm{O}$ content for the aged biochars. The formation of carboxylate groups on the surface increases negative surface charge and CEC but does not change anion exchange capacity (Lawrinenko et al., 2016; Oustriere et al., 2017).

It can be concluded from the FTIR analysis that the aging process has significantly changed the surface chemistry of the wheat straw biochars, and more significantly the ones produced at $400{ }^{\circ} \mathrm{C}$ and $500{ }^{\circ} \mathrm{C}$, compared to the one from $600{ }^{\circ} \mathrm{C}$. This result is related to the temperature of the pyrolysis process (i.e. the higher the applied temperature is the more the surface functionalities are reduced, and the more stable the produced biochar is). This temperature effect leaves more functionalities available for oxidation with $\mathrm{H}_{2} \mathrm{O}_{2}$ on the biochars from lower pyrolysis temperatures. The changes on the surface were mainly translated into increases in functional groups such as carboxyl and hydroxyl groups. The increase in surface functional groups with $\mathrm{H}_{2} \mathrm{O}_{2}$ oxidation, e.g. polar groups, can potentially lead to better performance in applications such as liquid-phase adsorption and soil amendment, with increased retention of nutrients for plant growth and lower mobility of PTE such as Zn (Bashir et al., 2018; Kumar et al., 2018). For example, the retention of PTE ions such as Cd (II) was found to be favored by the presence of O-containing functional groups that act as binding sites, such as $-\mathrm{OH}$ and $-\mathrm{COOH}$, e.g. through complexation (Sun et al., 2014; Zuo et al., 2016).

\subsection{Changes in soil pore water $\mathrm{Cd}$ concentration and $\mathrm{pH}$}

The Cd concentration in rhizon soil pore water extracts over a 6 months of period is depicted in

Fig. 2. When the soil was mixed with biochar, in the initial soil and biochar mixtures, the $\mathrm{pH}$ had values of $8.1 \pm$ 0.3 (F400), $5.2 \pm 0.1$ (A400), $8.8 \pm 0.1$ (F500), $6.3 \pm 0.1$ (A500), $9.1 \pm 0.2$ (F600) and $7.5 \pm 0.2$ (A600). Rhizon soil moisture samplers can be used to sample the dissolved components in soil solution. The $\mathrm{Cd}$ concentration in the soil pore water is mainly governed by $\mathrm{pH}, \mathrm{CEC}$ and the total $\mathrm{Cd}$ concentration in soil (Meers et al., 2007). At the end of the first month of the incubation, both fresh and aged biochar produced at $400{ }^{\circ} \mathrm{C}(260 \mu \mathrm{g} / \mathrm{L}$ and 387 $\mu \mathrm{g} / \mathrm{L}$ in F400 and A400 respectively $)$ and $500{ }^{\circ} \mathrm{C}(212 \mu \mathrm{g} / \mathrm{L}$ and $320 \mu \mathrm{g} / \mathrm{L}$ in F500 and A500 respectively $)$ had higher $\mathrm{Cd}$ concentrations than the soil only $(157 \mu \mathrm{g} / \mathrm{L})$ treatment. Only fresh and aged biochars produced at 600 respectively). 


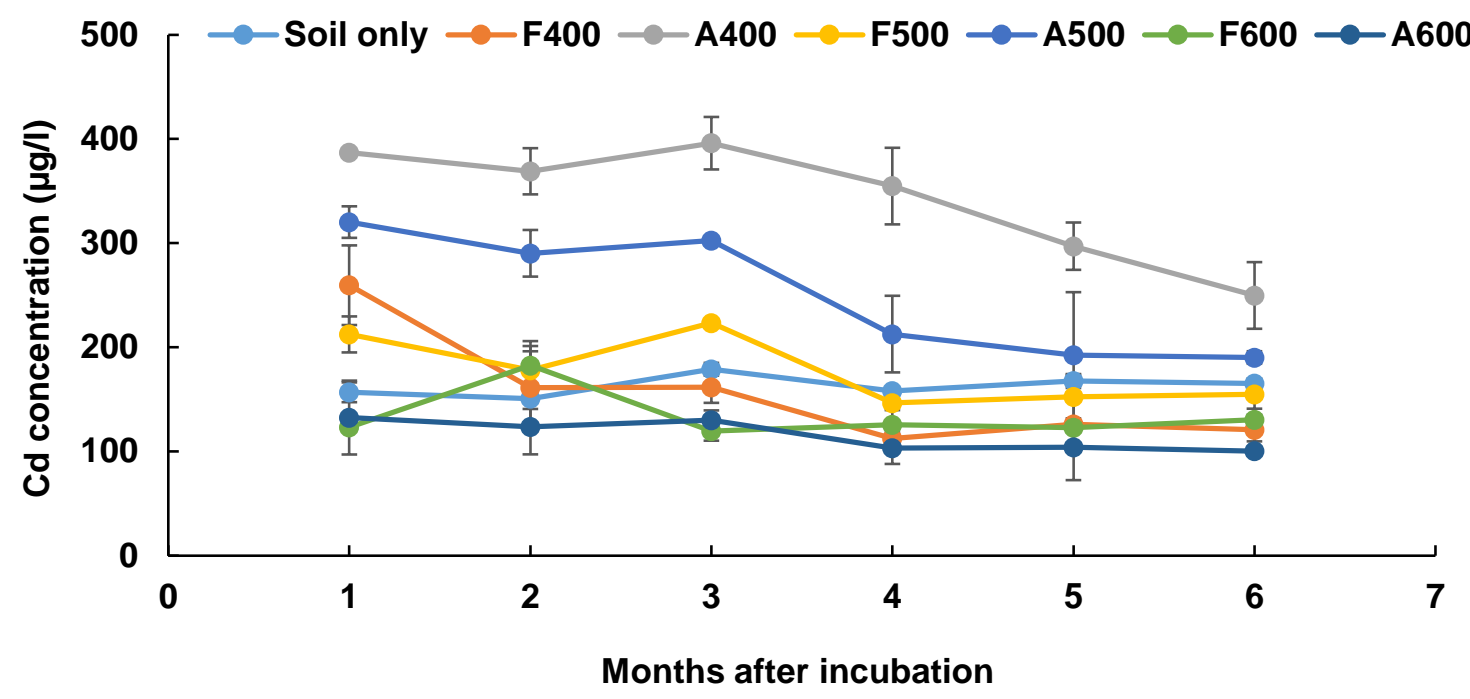

318 Fig. $2 \mathrm{Cd}$ concentration in rhizon extracts $(\mu \mathrm{g} / \mathrm{L})(\operatorname{mean} \pm \mathrm{sd}, \mathrm{n}=3)$ during a six month incubation experiment.

319 At the end of the six month of incubation period, A400 showed a significantly higher level of Cd concentration in 320 the soil solution than the other treatments. Except the A400 treatment, there were no significance differences between the other treatments. This observation is supported by the data and trends of soil solution $\mathrm{pH}$ shown in Fig 3.

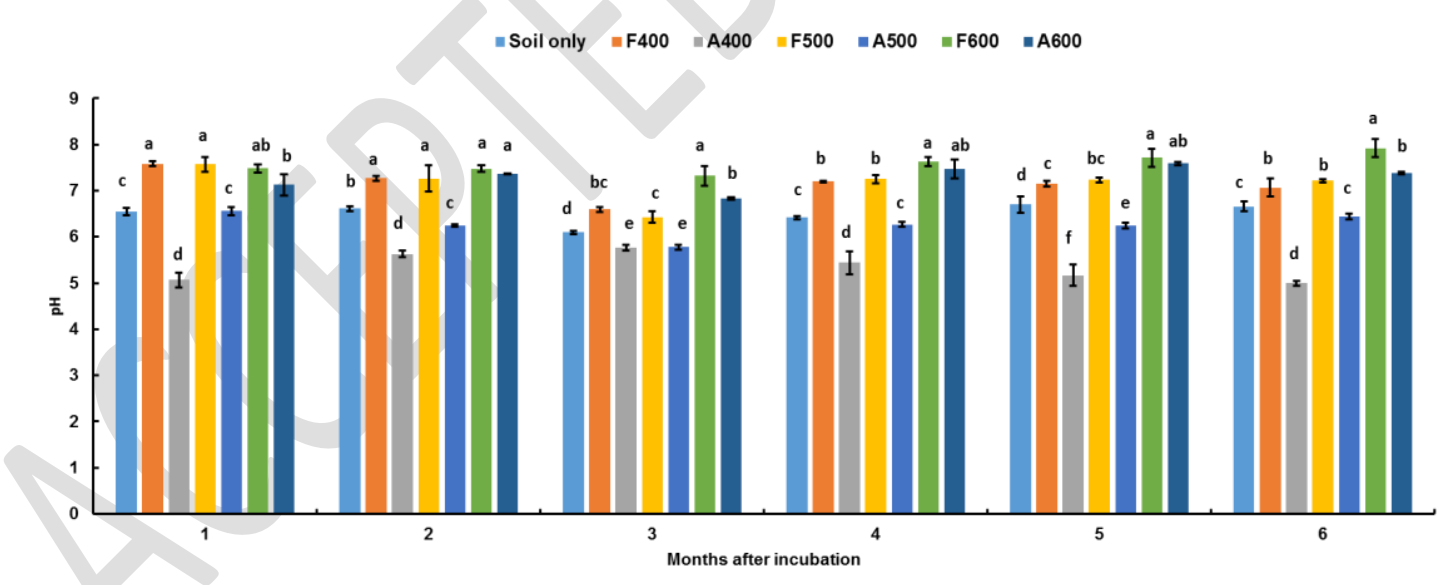

Fig. $3 \mathrm{pH}$ in rhizon extracts (mean $\pm \mathrm{sd}, \mathrm{n}=3$ ) during a six month incubation experiment. Same letters indicate no significant difference at $\mathrm{p}<0.05$ level.

At the beginning of the incubation, A600 and F600 showed a higher pH compared to the other treatments. Also, at the end of the 6 months of incubation, Cd concentration in the soil solution was well aligned with the pH of the soil solution. Previous studies (Xu et al., 2018; Yang et al., 2016) reported that alkalinisation is the dominant process in $\mathrm{Cd}$ immobilization, which controls the release of $\mathrm{Cd}$ into the soil solution. Heavy metal immobilization 
capacity of biochar depends on several factors, such as the physicochemical characteristics of biochar, the

331

332

333

334

335 application dose of biochar in soil, the Cd concentration in the soil and the physicochemical properties of the soil such as $\mathrm{pH}$, redox potential, organic matter content, moisture content and the nature of the mineral constituents (Bandara et al., 2019; Xu et al., 2013). Based on the above findings, except for the A400 biochar treatment, all aged biochar treatments (A500 and A600) efficiently immobilized the $\mathrm{Cd}$ in both the exchangeable fraction and the rhizon pore water extracts. According to past studies (Reverchon et al., 2015; Tan et al., 2015; Zhao et al., 2020), there are few underlying mechanisms that can be identified as responsible for Cd immobilization in soil. These include the formation of insoluble compounds (precipitates) via reactions between $\mathrm{Cd}^{2+}$ ions and biochar mineral constituents (i.e., carbonates and phosphates), physical adsorption of $\mathrm{Cd}^{2+}$ in soil pores and/or in biochar pores through transformed metal species via redox reactions, formation of surface complexation between $\mathrm{Cd}^{2+}$ and functional groups on biochar surface (i.e., hydroxide and carboxylic groups), electrostatic interaction between biochar and $\mathrm{Cd}^{2+}$, and ion exchange via $\mathrm{Cd}^{2+}$ and protons and alkaline metals in biochar.

Increase in $\mathrm{pH}$ through the addition of lime or limestone decreases the metal solubility through sorption and the formation of less soluble precipitates (Ettler, 2016; Liang et al., 2014). Therefore, having a constant pH in soil and soil pore water is crucial in remediation processes (Van Poucke et al., 2020; Zheng et al., 2017). Moreover, Qi et al., (2018) observed a higher solubility of Cd under acidic conditions. Reduction in Cd mobility in soil pore water under acidic conditions could be due to a reduction in surface complexation of $\mathrm{Cd}^{2+}$ onto biochar surface functionalities (Qi et al., 2018). The increase in soil $\mathrm{pH}$ reduces the bioavailable Cd due to an increase in surface negative charges and therefore an increase in negative charge densities and exchange sites. This is well backed up by the decrease in $\mathrm{Cd}$ in pore water when biochar $\mathrm{pH}$ increases (Fig A.1. in appendix). The presence of highly dissolved organic carbon (DOC) could increase the metal mobility through an increase of soluble organometallic complexes which could decrease the adsorption of metals (Egene et al., 2018). Dong et al., (2017) observed that aged biochar consisted of smooth surfaces, larger pores and newly formed small pores. Due to this, even with the reduced $\mathrm{pH}$ in aged biochar added treatments, it was possible to reduce the pore water Cd concentration due to an increase in sorption sites (Fig 2).

Oxidation of biochar could introduce additional binding sites for $\mathrm{Cd}^{2+}$ through an increase in functional groups on the biochar surface. As mentioned in section 3.1.4., the strong bands related to carbonyl and carboxyl functionalities on aged low temperature biochar (A500 and A400) are likely to contribute to binding of $\mathrm{Cd}^{2+}$ and reduce their availability in the pore water (Tan et al., 2015). A500 and A600 performed well even though those biochars have acidic $\mathrm{pH}$ compared to A400. Therefore, availability of $\mathrm{Cd}$ in pore water is governed by the 
combined effect of $\mathrm{pH}$ and surface complexation via functional groups on the surface of biochar. In this study it appears that the effectiveness of this process is mainly governed by soil pore water $\mathrm{pH}$ (Appendix, Fig A.1.).

\subsection{Sequential extraction}

The distribution of the different fractions of $\mathrm{Cd}$ in the soil among the different treatments are presented in Fig 4. The Cd concentration in different geochemical soil fractions gives an idea about its mobility in the soil. The exchangeable fraction contains the PTEs that affect the sorption and desorption processes. PTEs that are bound to Fe and Mn oxides and unstable under anoxic conditions represent the reducible fraction.

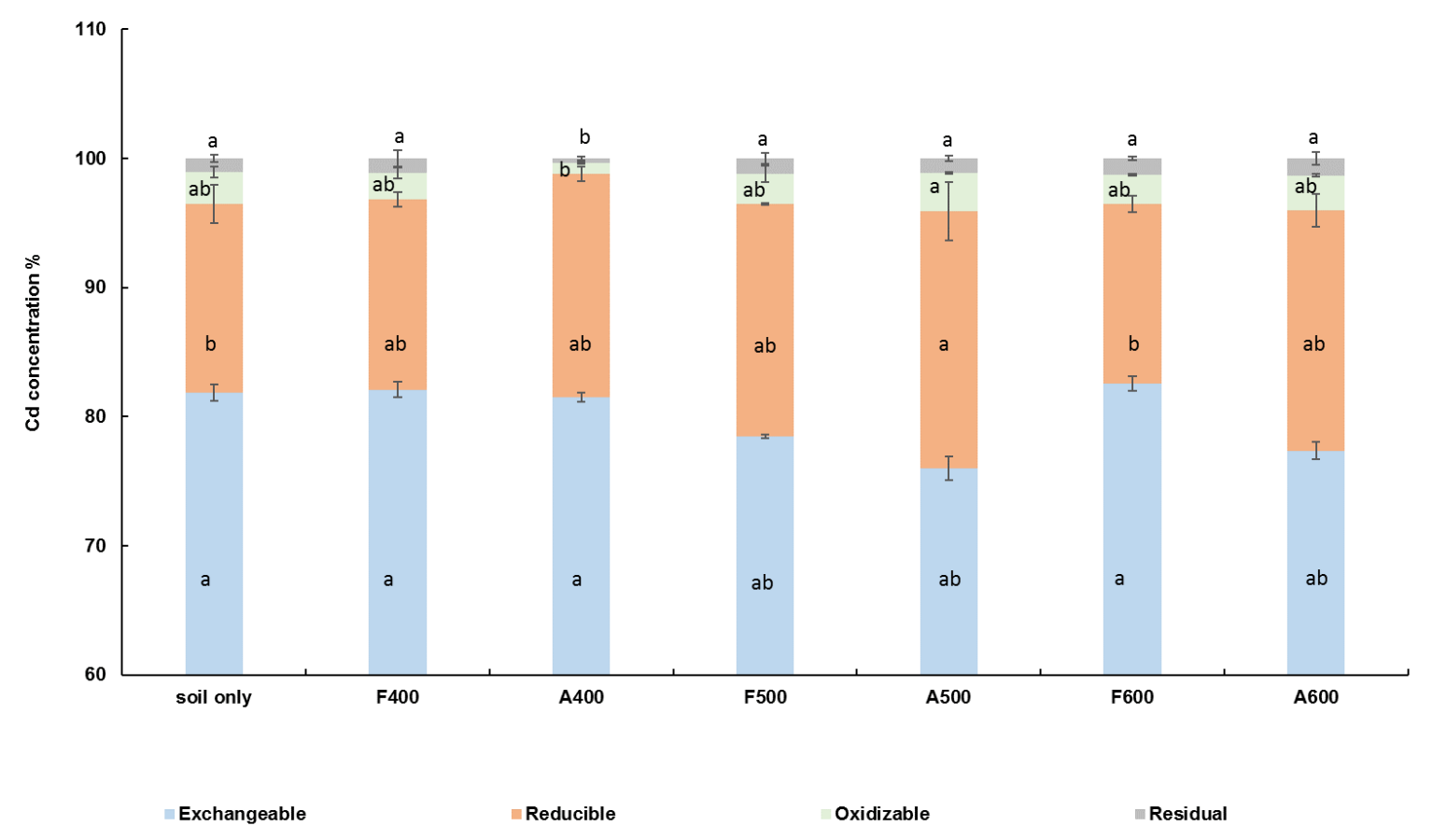

Fig. 4 Distribution (in \%) of different fractions of $\mathrm{Cd}$ in soil among different treatments (mean $\pm \mathrm{sd}, \mathrm{n}=3$ ). Same letters indicate no significant difference at $\mathrm{p}<0.05$ level

The organic matter-bound fraction contains the PTEs bound to organic matter derived from plant and animal detritus materials (Rauret et al., 1999; Tessier et al., 1979). Those PTEs could be released to the soil solution due to the degradation of organic matter by oxidation. The residual fraction, which is mostly the unavailable fraction contains the PTEs trapped into primary and secondary mineral structures (Tessier et al., 1979).

In the exchangeable fraction, only F500, A500, and A600 had a significantly lower concentration of Cd than the other treatments (F400, A400 and F600) and the control. The exchangeable fraction in soil mainly depends on the soil $\mathrm{pH}$ and the availability of binding sites. The alkalinity of biochar is beneficial to Cd binding. However, this could be less effective with an increase in soil acidification or upon aging of biochar (Qian et al., 2015; Xu et al., 
2016). On the other hand, aging of biochar could increase the biochar's $\mathrm{H} / \mathrm{C}$ molar ratio, $\mathrm{O} / \mathrm{C}$ molar ratio, specific surface area and porosity (Hardy et al., 2017). Aged biochars could have more acidic functionalities (Fig 1) and be more hydrophilic (Lian and Xing, 2017). Thus, aged biochars can attract more positively charged cations like $\mathrm{Cd}^{2+}$ through electrostatic attraction and surface complexation. This is well supported by the lower Cd concentrations in the exchangeable fraction in A500 and A600 (Fig. 4).

As mentioned in section 3.2, at the end of the six month incubation period, soil pore water Cd was significantly higher only in A400 compared to the other treatments including soil only. The difference in the observation between the pore water $\mathrm{Cd}$ and $\mathrm{CaCl}_{2}$-extractable $\mathrm{Cd}$ may be due to a difference in the extraction methods. Both pore water extraction by rhizon soil moisture sampling and $\mathrm{CaCl}_{2}$ extraction occur under actual soil $\mathrm{pH}$ without buffering. However, compared to rhizon extraction, $\mathrm{CaCl}_{2}$ extraction is accompanied by strong divalent cation exchange. Also, chloride as a counter ion could cause additional complexation and mobilization of PTEs (Meers et al., 2007). On the other hand, F400 and F600 had a lower amount of surface functionalities (i.e., carboxylic, carbonate and carbonyl functionalities) compared to A400 and A600. Consequently, the fresh biochars retain more $\mathrm{Cd}^{2+}$ ions into the exchangeable fraction even under favorable $\mathrm{pH}$ conditions (Fig. 4).

Only the A500 treatment had significantly higher levels of $\mathrm{Cd}$ in the reducible fraction than the other treatments. Reduction of Cd concentration in the exchangeable fraction in A500 can be connected to the increase in the Cd concentration in the reducible fraction. Besides A400, all the other treatments had significantly higher Cd concentrations in organic matter bound fraction. There was not any significant difference observed between soil only, F500, F600 and A600 treatments in organic matter bound fraction (Fig. 4). Organic matter can bind contaminants (i.e. cations) through its negatively charged sites (Ettler, 2016). Aging of biochar could increase its organic matter bound fraction due to an increase in negative charges on the biochar surface (Egene et al., 2018). This fits well with the significantly higher Cd concentrations in the organic matter bound fraction in aged biochar treatments (A500 and A600) than the fresh biochar treatments (Fig. 4). Moreover, having higher amount of acidic functionalities in aged biochar compared to fresh forms are favorable to surface complexation of Cd with organic matter (Fig. 1). Compared to soil only treatment, only A400 had significantly lower Cd concentration in the residual fraction. This may be due to an interruption of the $\mathrm{Cd}$ precipitation mechanisms due to higher acidity in the A400 treatment compared to the other treatments. 


\section{Conclusions}

406

407

408

409

410

411

412

413

414

415

416

417

The effect of aging on biochar's ability to immobilize $\mathrm{Cd}$ was tested using wheat straw biochar produced at different temperatures. Alkalinity and surface complexation via functional groups were identified as the primary mechanisms contributing to the $\mathrm{Cd}$ immobilization. Therefore, the changes with aging to these properties have been the key driver behind the differences in Cd immobilization between fresh and aged biochar. Aging has resulted in biochar with less alkaline $\mathrm{pH}$ and more acidic surface functionalities compared to fresh biochars. The severity of this effect was higher in biochar produced at a lower temperature compared to biochar produced at higher production temperatures. Both A500 and A600 effectively immobilized the $\mathrm{Cd}$ in pore water compared to A400. Hence, biochar produced at lower temperature is more effective in the short term, while biochar produced at higher production temperature is more beneficial for longer-term stabilizing effects. Thus, wheat straw biochar produced at higher production temperatures (i.e., $500{ }^{\circ} \mathrm{C}$ and $600{ }^{\circ} \mathrm{C}$ ) is more beneficial for long-term stabilizing of $\mathrm{Cd}$ in contaminated Lommel soil due to the favorable combined effect of $\mathrm{pH}$ and surface functionalities. The findings of this study provide insights to choose the production parameters in wheat straw biochar production while considering their aging effect to achieve a successful stabilization of $\mathrm{Cd}$ in contaminated soils.

\section{Declaration}

Ethics approval and consent to participate - Not applicable

Consent for publication - Not applicable

Availability of data and materials -All data generated or analysed during this study are included in this article.

Competing interests - The authors declare that they have no competing interests

Funding - Results incorporated in this paper received funding from the European Union's Horizon 2020 research and innovation programme under the Marie Skłodowska-Curie grant agreement No 721991.

Author contributions - DR: Conceptualization, investigation, formal analysis, visualization, writing original draft, FR: Investigation, writing-review and editing, RVP: Investigation, writing-review and editing, AVB, OM, EM, JW, and YY: Supervision, resources, writing-review and editing, FR: Supervision, resources, writing-review and editing and funding acquisition. All authors read and approved the final manuscript. 


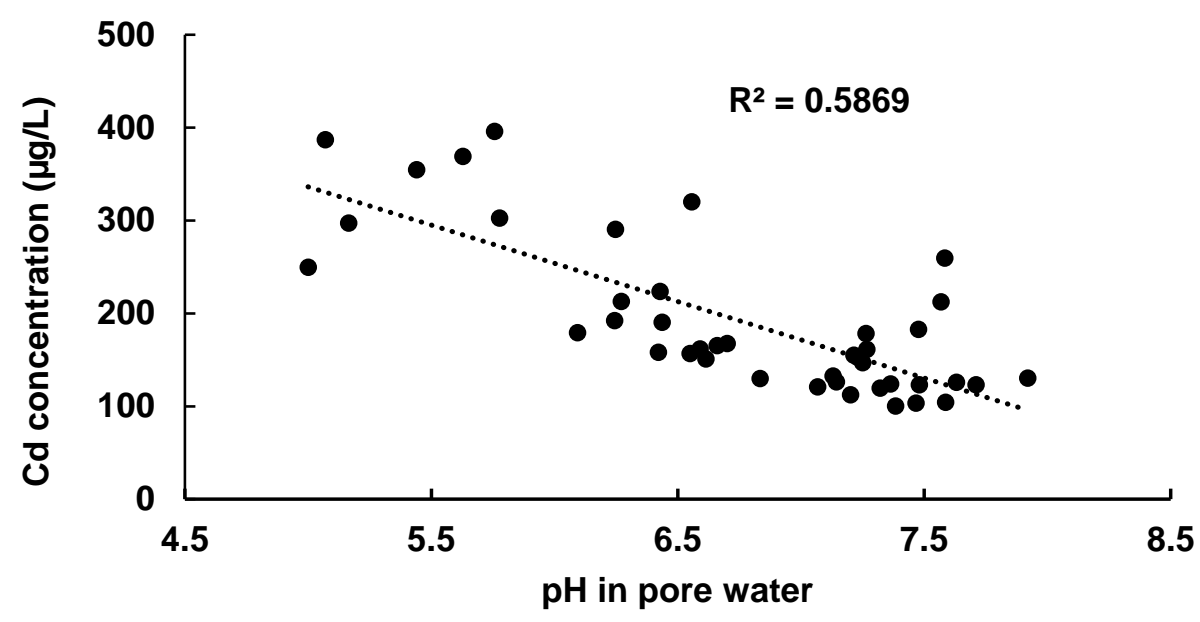

431

Fig A.1 Relationship between pore water $\mathrm{pH}$ and $\mathrm{Cd}$ concentration.

433

\section{References}

Ahmad, M., Rajapaksha, A.U., Lim, J.E., Zhang, M., Bolan, N., Mohan, D., Vithanage, M., Lee, S.S., Ok, Y.S., 2014. Biochar as a sorbent for contaminant management in soil and water: a review. Chemosphere 99, 1933. https://doi.org/10.1016/j.chemosphere.2013.10.071

Bakshi, S., Aller, D.M., Laird, D.A., Chintala, R., 2016. Comparison of the Physical and Chemical Properties of Laboratory and Field-Aged Biochars. J. Environ. Qual. 45, 1627. https://doi.org/10.2134/jeq2016.02.0062

Bandara, T., Franks, A., Xu, J., Bolan, N., Wang, H., Tang, C., 2019. Technology Chemical and biological immobilization mechanisms of potentially toxic elements in biochar-amended soils. Crit. Rev. Environ. Sci. Technol. 3389. https://doi.org/10.1080/10643389.2019.1642832

Bashir, S., Zhu, J., Fu, Q., Hu, H., 2018. Comparing the adsorption mechanism of Cd by rice straw pristine and KOH-modified biochar. Environ. Sci. Pollut. Res. 25, 11875-11883. https://doi.org/10.1007/s11356-018$1292-\mathrm{z}$

Beesley, L., Moreno-Jiménez, E., Gomez-Eyles, J.L., Harris, E., Robinson, B., Sizmur, T., 2011. A review of biochars' potential role in the remediation, revegetation and restoration of contaminated soils. Environ. Pollut. 159, 3269-3282. https://doi.org/10.1016/j.envpol.2011.07.023 
Cao, T., Chen, W., Yang, T., He, T., Liu, Z., Meng, J., 2017. Surface characterization of aged biochar incubated in different types of soil. BioResources 12, 6366-6377. https://doi.org/10.15376/biores.12.3.6366-6377

Chen, D., Yu, X., Song, C., Pang, X., Huang, J., Li, Y., 2016. Effect of pyrolysis temperature on the chemical oxidation stability of bamboo biochar. Bioresour. Technol. 218, 1303-1306. https://doi.org/10.1016/j.biortech.2016.07.112

Cheng, C.H., Lehmann, J., Thies, J.E., Burton, S.D., 2008. Stability of black carbon in soils across a climatic gradient. J. Geophys. Res. Biogeosciences 113, 1-10. https://doi.org/10.1029/2007JG000642

Crombie, K., Mašek, O., Sohi, S.P., Brownsort, P., Cross, A., 2013. The effect of pyrolysis conditions on biochar stability as determined by three methods. GCB Bioenergy 5, 122-131. https://doi.org/10.1111/gcbb.12030

Cross, A., Sohi, S.P., 2013. A method for screening the relative long-term stability of biochar. GCB Bioenergy 5, 215-220. https://doi.org/10.1111/gcbb.12035

de la Rosa, J.M., Rosado, M., Paneque, M., Miller, A.Z., Knicker, H., 2018. Effects of aging under field conditions on biochar structure and composition: Implications for biochar stability in soils. Sci. Total Environ. 613614, 969-976. https://doi.org/10.1016/j.scitotenv.2017.09.124

Dharmakeerthi, R.S., Hanley, K., Whitman, T., Woolf, D., Lehmann, J., 2015. Organic carbon dynamics in soils with pyrogenic organic matter that received plant residue additions over seven years. Soil Biol. Biochem. 88, 268-274. https://doi.org/10.1016/J.SOILBIO.2015.06.003

Dong, X., Li, G., Lin, Q., Zhao, X., 2017. Quantity and quality changes of biochar aged for 5 years in soil under field conditions. Catena 159, 136-143. https://doi.org/10.1016/j.catena.2017.08.008

Egene, C.E., Poucke, R. Van, Ok, Y.S., Meers, E., Tack, F.M.G., 2018. Impact of organic amendments ( biochar , compost and peat ) on $\mathrm{Cd}$ and $\mathrm{Zn}$ mobility and solubility in contaminated soil of the Campine region after three years. Sci. Total Environ. 626, 195-202. https://doi.org/10.1016/j.scitotenv.2018.01.054

Enders, A., Sohi, S., Lehmann, J., Balwant, S., 2017. Total elemental analysis of metals and nutrients in biochar, in: Biochar: A Guide to Analytical Methods. Csiro Publishing, pp. 95-108.

Ettler, V., 2016. Soil contamination near non-ferrous metal smelters : A review. Appl. Geochemistry J. 64, 56-74. https://doi.org/10.1016/j.apgeochem.2015.09.020 

Agriculture Organization of the United Nations (FAO).

Hardy, B., Leifeld, J., Knicker, H., Dufey, J.E., Deforce, K., Cornélis, J., 2017. Long term change in chemical properties of preindustrial charcoal particles aged in forest and agricultural temperate soil. Org. Geochem. 107, 33-45. https://doi.org/10.1016/j.orggeochem.2017.02.008

He, E., Yang, Y., Xu, Z., Qiu, H., Yang, F., Peijnenburg, W.J.G.M., Zhang, W., Qiu, R., Wang, S., 2019. Two years of aging influences the distribution and lability of metal(loid)s in a contaminated soil amended with different biochars. Sci. Total Environ. 673, 245-253. https://doi.org/10.1016/j.scitotenv.2019.04.037

Heitkötter, J., Marschner, B., 2015. Interactive effects of biochar ageing in soils related to feedstock, pyrolysis temperature , and historic charcoal production it. Geoderma 245-246, 56-64. https://doi.org/10.1016/j.geoderma.2015.01.012

Huff, M.D., Lee, J.W., 2016. Biochar-surface oxygenation with hydrogen peroxide. J. Environ. Manage. 165, 1721. https://doi.org/10.1016/j.jenvman.2015.08.046

Kumar, A., Joseph, S., Tsechansky, L., Privat, K., Schreiter, I.J., Schüth, C., Graber, E.R., 2018. Biochar aging in contaminated soil promotes $\mathrm{Zn}$ immobilization due to changes in biochar surface structural and chemical properties. Sci. Total Environ. 626, 953-961. https://doi.org/10.1016/j.scitotenv.2018.01.157

Lawrinenko, M., Laird, D.A., Johnson, R.L., Jing, D., 2016. Accelerated aging of biochars: Impact on anion exchange capacity. Carbon N. Y. 103, 217-227. https://doi.org/10.1016/j.carbon.2016.02.096

Lehmann, J., Joseph, S., 2009. A Future for Biochar in Vermont. Biochar Environ. Manag. Sci. Technol. 416.

Lian, F., Xing, B., 2017. Black Carbon ( Biochar ) In Water / Soil Environments : Molecular Structure , Sorption , Stability, and Potential Risk. Environ. Sci. Technol. https://doi.org/10.1021/acs.est.7b02528

Liang, B., Lehmann, J., Solomon, D., Sohi, S., Thies, J.E., Skjemstad, J.O., Luizão, F.J., Engelhard, M.H., Neves, E.G., Wirick, S., 2008. Stability of biomass-derived black carbon in soils. Geochim. Cosmochim. Acta 72, 6069-6078. https://doi.org/10.1016/j.gca.2008.09.028

Liang, Y., Cao, X., Zhao, L., Arellano, E., 2014. Biochar- and phosphate-induced immobilization of heavy metals in contaminated soil and water: Implication on simultaneous remediation of contaminated soil and groundwater. Environ. Sci. Pollut. Res. 21, 4665-4674. https://doi.org/10.1007/s11356-013-2423-1 
Lomaglio, T., Hattab-Hambli, N., Miard, F., Lebrun, M., Nandillon, R., Trupiano, D., Scippa, G.S., Gauthier, A., Motelica-Heino, M., Bourgerie, S., Morabito, D., 2018. Cd, Pb, and Zn mobility and (bio)availability in contaminated soils from a former smelting site amended with biochar. Environ. Sci. Pollut. Res. 25, 2574425756. https://doi.org/10.1007/s11356-017-9521-4

Masek, O., 2016. Biochar in thermal and thermochemical biorefineries-production of biochar as a coproduct., in: Handbook of Biofuels Production. Woodhead Publishing.

Mašek, O., Brownsort, P., Cross, A., Sohi, S., 2013. Influence of production conditions on the yield and environmental stability of biochar, in: Fuel. pp. 151-155. https://doi.org/10.1016/j.fuel.2011.08.044

Meers, E., Du Laing, G., Unamuno, V., Ruttens, A., Vangronsveld, J., Tack, F.M.G., Verloo, M.G., 2007. Comparison of cadmium extractability from soils by commonly used single extraction protocols. Geoderma 141, 247-259. https://doi.org/10.1016/j.geoderma.2007.06.002

Meers, E., Slycken, S. Van, Adriaensen, K., Ruttens, A., Vangronsveld, J., Laing, G. Du, Witters, N., Thewys, T., Tack, F.M.G., 2010. The use of bio-energy crops ( Zea mays ) for 'phytoattenuation' of heavy metals on moderately contaminated soils : A field experiment. Chemosphere 78, 35-41. https://doi.org/10.1016/j.chemosphere.2009.08.015

Meers, E., Unamuno, V., Vandegehuchte, M., Vanbroekhoven, K., Geebelen, W., Samson, R., Vangronsveld, J., Diels, L., Ruttens, A., Du Laing, G., Tack, F., 2005. Soil-solution speciation of Cd as affected by soil characteristics in unpolluted and polluted soils. Environ. Toxicol. Chem. 24, 499-509. https://doi.org/10.1897/04-231R.1

Mia, S., Dijkstra, F.A., Singh, B., 2017. Long-Term Aging of Biochar: A Molecular Understanding With Agricultural and Environmental Implications, 1st ed, Advances in Agronomy. Elsevier Inc. https://doi.org/10.1016/bs.agron.2016.10.001

Moreno-Castilla, C., Ferro-Garcia, M.A., Joly, J.P., Bautista-Toledo, I., Carrasco-Marin, F., Rivera-Utrilla, J., 1995. Activated carbon surface modifications by nitric acid, hydrogen peroxide, and ammonium peroxydisulfate treatments. Langmuir 11, 4386-4392.

Mukherjee, A., Zimmerman, A.R., Hamdan, R., Cooper, W.T., 2014. Physicochemical changes in pyrogenic organic matter ( biochar ) after 15 months of field aging 5194. https://doi.org/10.5194/se-5-693-2014 
Nachenius, R.W., Ronsse, F., Venderbosch, R.H., Prins, W., 2013. Biomass Pyrolysis, in: Chemical Engineering for Renewables Conversion. Elsevier Inc., pp. 75-139. https://doi.org/10.1016/B978-0-12-386505-2.00002$\mathrm{X}$

Oustriere, N., Marchand, L., Rosette, G., Friesl-Hanl, W., Mench, M., 2017. Wood-derived-biochar combined with compost or iron grit for in situ stabilization of $\mathrm{Cd}, \mathrm{Pb}$, and $\mathrm{Zn}$ in a contaminated soil. Environ. Sci. Pollut. Res. 24, 7468-7481. https://doi.org/10.1007/s11356-017-8361-6

Palansooriya, K.N., Shaheen, S., Chen, S.S., Tsang, D.C.W., Hashimoto, Y., Hou, D., Bolan, N.S., Rinklebe, J., Ok, Y.S., 2020. Soil amendments for immobilization of potentially toxic elements in contaminated soils : A critical review. Environ. Int. 134, 105046. https://doi.org/10.1016/j.envint.2019.105046

Qi, F., Lamb, D., Naidu, R., Bolan, N.S., Yan, Y., Sik, Y., Mahmudur, M., Choppala, G., 2018. Cadmium solubility and bioavailability in soils amended with acidic and neutral biochar. Sci. Total Environ. 611, 1457-1466. https://doi.org/10.1016/j.scitotenv.2017.08.228

Qian, L., Chen, M., Chen, B., 2015. Competitive adsorption of cadmium and aluminum onto fresh and oxidized biochars during aging processes. J Soils Sediments 1130-1138. https://doi.org/10.1007/s11368-015-1073-y

Rauret, G., López-Sánchez, J.F., Sahuquillo, A., Rubio, R., Davidson, C., Ure, A., Quevauviller, P., 1999. Improvement of the BCR three step sequential extraction procedure prior to the certification of new sediment and soil reference materials. J. Environ. Monit. 1, 57-61. https://doi.org/10.1039/a807854h

Rechberger, M. V, Kloss, S., Rennhofer, H., Tintner, J., Watzinger, A., Soja, G., Lichtenegger, H., Zehetner, F., 2017. Changes in biochar physical and chemical properties: Accelerated biochar aging in an acidic soil. Carbon N. Y. 115, 209-219. https://doi.org/10.1016/j.carbon.2016.12.096

Ronsse, F., Nachenius, R.W., Prins, W., 2015. Carbonization of Biomass, in: Recent Advances in ThermoChemical Conversion of Biomass. pp. 293-324.

Ronsse, F., Van Hecke, S., Dickinson, D., Prins, W., 2013. Production and characterization of slow pyrolysis biochar: influence of feedstock type and pyrolysis conditions. Gcb Bioenergy 5, 104-115. https://doi.org/10.1111/gcbb.12018

Singh, B., Fang, Y., Cowie, B.C.C., Thomsen, L., 2014. Organic Geochemistry NEXAFS and XPS characterisation of carbon functional groups of fresh and aged biochars 77, 1-10. 
Sun, J., Lian, F., Liu, Z., Zhu, L., Song, Z., 2014. Ecotoxicology and Environmental Safety Biochars derived from various crop straws : Characterization and Cd ( II ) removal potential. Ecotoxicol. Environ. Saf. 106, 226231. https://doi.org/10.1016/j.ecoenv.2014.04.042

Tan, X., Liu, Y., Gu, Y., Zeng, G., Wang, X., Hu, X., Sun, Z., Yang, Z., 2015. Immobilization of Cd(II) in acid soil amended with different biochars with a long term of incubation. Environ. Sci. Pollut. Res. 22, 1259712604. https://doi.org/10.1007/s11356-015-4523-6

Tessier, A., Campbell, P.G.C., Bisson, M., 1979. Sequential Extraction Procedure for the Speciation of Particulate Trace Metals. Anal. Chem. 51, 844-851.

Van Poucke, R., Ainsworth, J., Maeseele, M., Ok, Y.S., Meers, E., Tack, F.M.G., 2018. Chemical stabilization of Cd-contaminated soil using biochar. Appl. Geochemistry 88, 122-130. https://doi.org/10.1016/j.apgeochem.2017.09.001

Van Poucke, R., Meers, E., Tack, F.M.G., 2020. Leaching behavior of Cd, Zn and nutrients (K, P, S) from a contaminated soil as affected by amendment with biochar. Chemosphere 245, 125561. https://doi.org/10.1016/j.chemosphere.2019.125561

Van Ranst, E., Verloo, M., Demeyer, A., Pauwels, J., 1999. Manual for the soil chemistry and fertility laboratory: analytical methods for soils and plants equipment, and management of consumables.

Wang, H.Y., Chen, P., Zhu, Y.G., Cen, K., Sun, G.X., 2019. Simultaneous adsorption and immobilization of As and $\mathrm{Cd}$ by birnessite-loaded biochar in water and soil. Environ. Sci. Pollut. Res. 26, 8575-8584. https://doi.org/10.1007/s11356-019-04315-x

Wang, L., Ok, Y.S., Tsang, D.C.W., Alessi, D.S., Rinklebe, J., Wang, H., Mašek, O., Hou, R., O’Connor, D., Hou, D., 2020. New Trends in Biochar Pyrolysis and Modification Strategies: Feedstock, Pyrolysis Conditions, Sustainability Concerns and Implications for Soil Amendment. Soil Use Manag. 1-29. https://doi.org/10.1111/sum.12592

Weber, K., Quicker, P., 2018. Properties of biochar. Fuel 217, 240-261. https://doi.org/10.1016/j.fuel.2017.12.054

WHO, 2007. Health risks of heavy metals from long-range transboundary air pollution. World Health Organization. 
Xu, C., Chen, H. xiang, Xiang, Q., Zhu, H. hua, Wang, S., Zhu, Q. hong, Huang, D. you, Zhang, Y. zhu, 2018. Effect of peanut shell and wheat straw biochar on the availability of $\mathrm{Cd}$ and $\mathrm{Pb}$ in a soil-rice (Oryza sativa L.) system. Environ. Sci. Pollut. Res. 25, 1147-1156. https://doi.org/10.1007/s11356-017-0495-z

Xu, X., Cao, X., Zhao, L., Wang, H., Yu, H., Gao, B., 2013. Removal of Cu, Zn, and Cd from aqueous solutions by the dairy manure-derived biochar. Environ. Sci. Pollut. Res. 20, 358-368. https://doi.org/10.1007/s11356-012-0873-5

Xu, Y., Fang, Z., Tsang, E.P., 2016. In situ immobilization of cadmium in soil by stabilized biochar-supported iron phosphate nanoparticles. Environ. Sci. Pollut. Res. 23, 19164-19172. https://doi.org/10.1007/s11356016-7117-z

Yang, X., Liu, J., McGrouther, K., Huang, H., Lu, K., Guo, X., He, L., Lin, X., Che, L., Ye, Z., Wang, H., 2016. Effect of biochar on the extractability of heavy metals $(\mathrm{Cd}, \mathrm{Cu}, \mathrm{Pb}$, and $\mathrm{Zn})$ and enzyme activity in soil. Environ. Sci. Pollut. Res. 23, 974-984. https://doi.org/10.1007/s11356-015-4233-0

Yang, Y., Heaven, S., Venetsaneas, N., Banks, C.J., Bridgwater, A. V, 2018. Slow pyrolysis of organic fraction of municipal solid waste ( OFMSW ): Characterisation of products and screening of the aqueous liquid product for anaerobic digestion. Appl. Energy 213, 158-168. https://doi.org/10.1016/j.apenergy.2018.01.018

Yu, Y., Yang, Y., Cheng, Z., Blanco, P.H., Liu, R., Bridgwater, A. V, Cai, J., 2016. Pyrolysis of Rice Husk and Corn Stalk in Auger Reactor . 1. Characterization of Char and Gas at Various Temperatures. Energy \& Fuels. https://doi.org/10.1021/acs.energyfuels.6b02276

Zhao, L., Cao, X., Mašek, O., Zimmerman, A., 2013. Heterogeneity of biochar properties as a function of feedstock sources and production temperatures. J. Hazard. Mater. 256-257, 1-9. https://doi.org/10.1016/J.JHAZMAT.2013.04.015

Zheng, R., Li, C., Sun, G., Xie, Z., Chen, J., Wu, J., Wang, Q., 2017. The influence of particle size and feedstock of biochar on the accumulation of $\mathrm{Cd}, \mathrm{Zn}, \mathrm{Pb}$, and As by Brassica chinensis L. Environ. Sci. Pollut. Res. 24, 22340-22352. https://doi.org/10.1007/s11356-017-9854-z

Zuo, X., Liu, Z., Chen, M., 2016. Bioresource Technology Effect of H 2 O 2 concentrations on copper removal using the modified hydrothermal biochar. Bioresour. Technol. 207, 262-267. https://doi.org/10.1016/j.biortech.2016.02.032 
611 